\title{
Metodologías psicoacústicas en la determinación de desórdenes psicológicos
}

\section{Psychoacoustic methodologies in the determination of psychological disorders}

\section{Resumen}

La ansiedad es uno de los principales problemas de las sociedades modernas. La sobre-activación de un organismo a un estímulo en particular, genera una reacción en cadena, que altera la cotidianidad del individuo, y lo bloquea psicológicamente, en algunas situaciones. En tratamiento terapéutico existen varias estrategias que buscan el control sobre estas reacciones y la ponderación de los estímulos, entre estas, las terapias fundadas en estimulación sonora. Dentro del tratamiento músico-terapéutico, se buscan procedimientos que permitan tener control sobre los procesos de reacción emocional y fisiológicos, midiendo el impacto a través de instrumentos que revelan las respuestas fisiológicas. De esta manera, encontrar una correlación entre estos procedimientos ha motivado la búsqueda de metodologías psicométricas.

\section{Palabras clave}

Psychometría, métodos subjetivos, escalas, evaluación de desórdenes psicológicos.

\section{Abstract}

Anxiety is one of the main problems of modern societies. The overloaded activation of an organism to a particular stimulus, generates a reaction-chain, that alters the cotidia-

Ingeniero Electrónico, Magíster en Radioelectrónica y Doctor en Acústica, Universidad Técnica de Praga. Docente Investigador de la Facultad de Ingeniería y Líder del Semillero de Investigación de "Sistemas de Compresión Perceptual de Audio», Universidad de San Buenaventura, Bogotá. E-mail: mherrera@usbbog.edu.co

** Ingeniero de Sonido, Especialista en Pedagogía y Docencia Universitaria, Universidad de San Buenaventura, Bogotá. Docente Investigador de la Facultad Ingeniería, Universidad de San Buenaventura, Bogotá. E-mail: rrincon@usbbog.edu.co

*** Ingeniero Electrónico y Especialista en Teleinformática, Universidad Distrital Francisco José de Caldas. Docente Investigador, Universidad Manuela Beltrán. E-mail: carlos.vargas@docentes.umb.edu.co 
nity of the individuum, and blocks him psychologically, in some determined situations. In therapeutic treatment, there are diverse strategies that search for the control over these reactions and the weighting of the stimulus, among them, the therapy founded on sound stimulation. Within the musico-therapeutical treatment, the need for finding procedures that would allow control over the emotional and/or physiological reaction processes, measuring impact through instruments that reveal physiological responses is searched. In this way, to find a correlation between these procedures has motivated this survey of psychometric methodologies.

\section{Keywords}

Psychometry, Subjective Methods, Scales, Evaluation of psychological disorders.

\section{Introduction}

Subjective methods rely on the statistical evaluation of subjective methodologies based on psychometric principles. A maximum interpersonal correlation, keeping a knowing constraint of intrapersonal reliability, based on the a-prior knowledge of critical signals is the aim. The goal is the achievement of objectivity, understanding objectivity as intrapersonal agreement.

Subjective assessments in psychoacoustic research are made based on psychophysics principles. It is important to have in mind the correct manners of test administration and the allowed statistical operations. The basic task of a psychoacoustic assessment can be described in the Fig. 1.

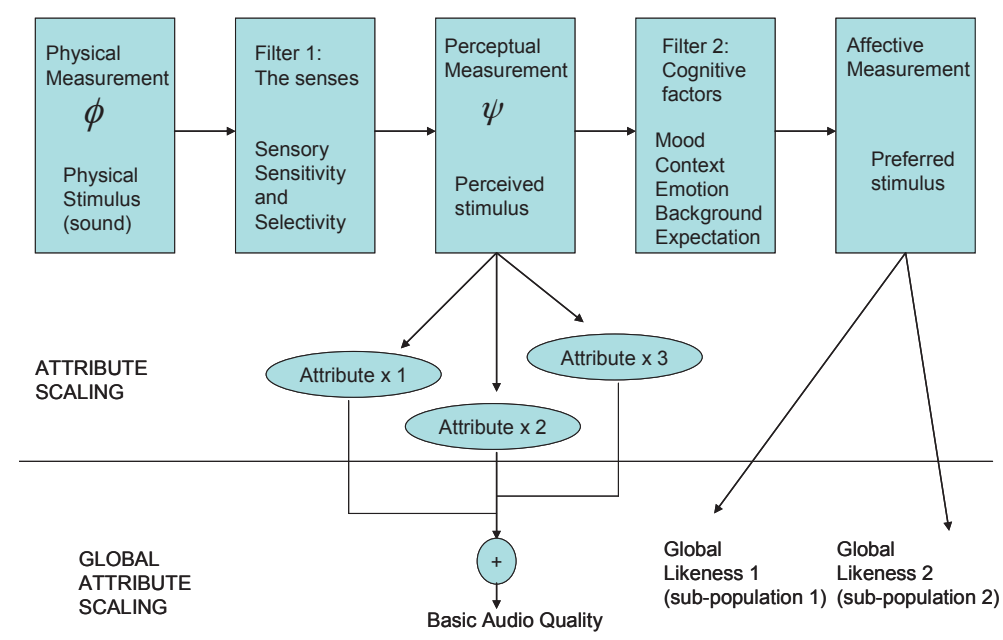

Figura. 1. Quantification of impression in a psychoacoustic task [32]

The physical stimulus is perceived by the senses (filter 1 ). This perceived stimulus can be evaluated according to some attribute (attribute scaling), or to some set of attributes leading to a global attribute evaluation. When the perceived stimulus is processed by cognitive factors (mood, context, emotion, background and/or expectation) affective measurement is approached. 


\section{Scales used in subjective measurements}

The response formats of subjects attending a psychoacoustic assessment generally consist of protocols containing scales. Four levels of measurement are distinguished: Nominal, ordinal, interval and ratio measurement scales [1].

\section{A. Nominal scale}

A number or a symbol as a label for a class or category is used in a nominal-scale measurement. Each number denotes uniquely a group or a class or a category. This procedure is the elemental classification procedure, where the frequency of some judgment will give us frequencies and contingency tables. The structure of the nominal scale is invariant to renaming, or changing the names of the groups or categories. Permutation procedures are also allowed. The graphic representation of the results for this type of measurement is given in the form of histograms.

\section{B. Ordinal scale}

In ordinal scale measurement we are introducing an order to the data. Data is evaluated with respect to some feature, and as a result, the data gets organized with respect to this feature. Attention should be given when evaluating data according to more than one feature. According to one feature, data will be ordered in a different way, than if we order it according to another feature. Separating the components of the variable becomes a necessity and the application of methods as multidimensional scaling (MDS) or factor analysis (FA) is performed. This operation of rank ordering is a classification in successive categories, as in the method of judgment in successive categories. This type of measurement remains invariant to isotonic transformations as multiplication, logarithm, or other linear operation to the values of the scale. The same statistics allowed for the ordinal scale are allowed for the nominal one, enhanced by medians, centiles, and rank-order coefficients of correlation.

\section{Interval scale}

This level of measurement enhances the above ones, in the sense that if the interval distance from $A$ to $B$ in a psychological scale is for example 5 , and the interval distance from $B$ to $C$ in a psychological scale is also 5 , then the psychological distances from $A$ to $B$, and from $B$ to $C$ are exactly the same. Moreover, it can be stated that the psychological distance from $A$ to $C$ is 10 . Examples of interval scales are the temperature scale or the Calendar time. Transformations allowed for this type of measurement are the linear ones.

Almost all the common statistical procedures can be applied to interval scales, as mean, the standard deviation, Pearson product-moment $r$, and others.

\section{Ratio scales}

Ratio scales enhances the previous scale methods. Ratio scales have absolute zeros. The most typical example is the measurement by the method of fractionation where the observer has to find pairs of stimuli that have a simple ratio like 1 to 2 . Stevens' son sca- 
le and his mel scale are examples of ratio scales. Similarity transformation is an allowed transformation for this type of measurement.

$$
y=b x
$$

$x \ldots$ original value

$y \ldots$ transformed value

$b>0 \ldots$ enlarging or shortening constant.

Descriptive characteristics for this type of test are the geometric mean and the coefficient of variation.

Tab. 1 describes the Stevens' hierarchic system of classification of types of measurement and scales. The table presents this classification from the lowest level of measurement to the highest one.

\begin{tabular}{|l|l|l|l|}
\hline Type of measurement & Type of scale & Scale form & Level of the measurement \\
\hline \hline Classification & Nominal & Non-metric & Lowest \\
\hline \multirow{3}{*}{ Quantification } & Ordinal & & \\
\cline { 2 - 2 } & Interval & Metric & Highest \\
\cline { 2 - 2 } & Ratio & & \\
\hline
\end{tabular}

Tab. 1. Stevens' hierarchic system of classification of types of measurement and scales [1]

\section{The method of constant stimuli}

In the method of constant stimuli, the experimenter presents to the listener stimuli, and the listener is asked to respond whether he experiments or not a certain, definite sensation or attribute, previously revealed to the listener in a training session. Responses are binary in the sense that the listeners answer yes/no, as illustrated in the Fig. 2.

The method of constant stimuli is usually performed in order to establish differential limens, and in the determination of other psychophysical descriptors.

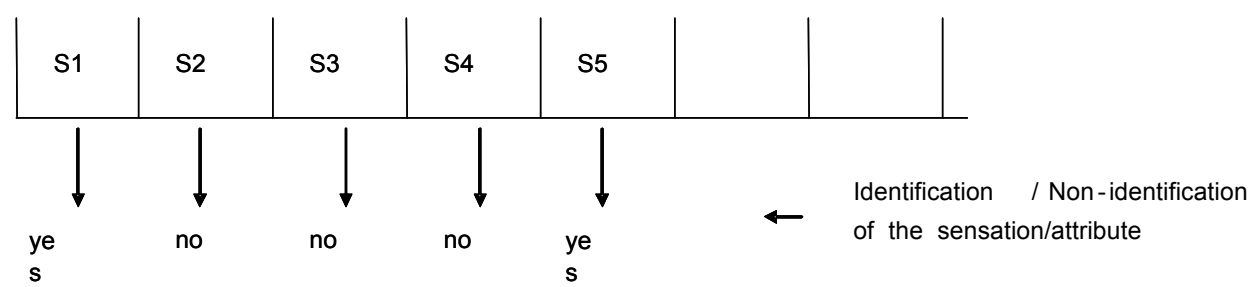

Fig. 2 The Constant Methods

The proportion of detected and non-detected responses is calculated for each stimulus level. The data are then plotted with stimulus intensity along the abscissa and the 
percentage of detection in the ordinate. The obtained curve is called the psychometric function.

A major source of variability is the continuous fluctuation of sensitivity which is present in biological sensory systems (as internal noise, or spontaneous activity). The described method is the normal graphic process for the determination of absolute limen.

\section{The Method of Successive Categories}

In this method, a scale is at disposition in which a definite set of categories is defined. The subject task is to map his subjective judgments, coming from subjective impressions to some acoustic stimuli, in order to evaluate to some degree the stimulus presented to him. Fig. 3 illustrates the principle. There are three planes in the figure: the judgment, the response and the stimulus planes. The judgment plane is divided in five categories, from $\mathrm{J} 1$ to J5. The boundaries or limits between each pair of categories are denoted by La, $L b, L c$ and $L d$. When a definite stimulus $S 9$ is perceived, a discriminal dispersion over the response plane is originated. The true response is located in the center of the distribution R9. Normal judgments of observers are placed below the distribution curve.

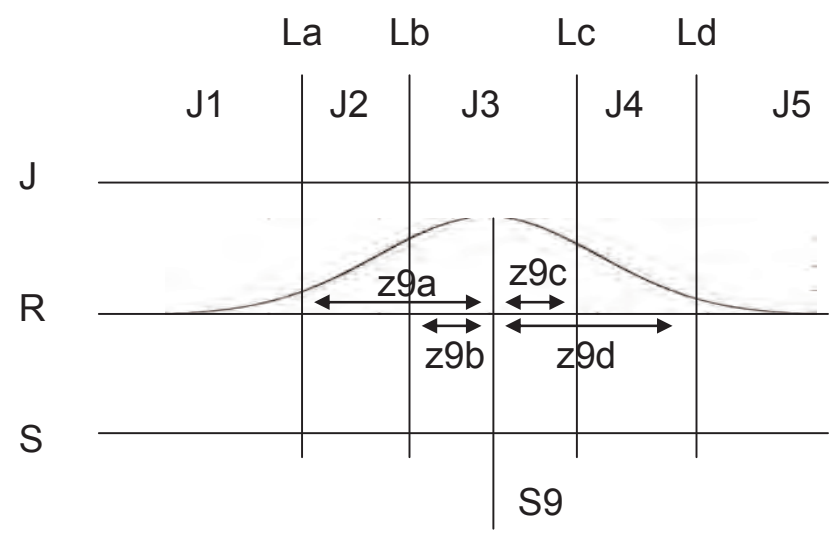

Fig. 3. Discriminal dispersions in the method of successive categories

In principle, all simple rating methods belong to this method. The general assumption is that the scale in which the categories are placed, form a psychological continuum. When there are two categories in the experiment, the dichotomy case appears. When designing an experiment with this method, the experimenter has two choices. Either, to design the verbal categories with respect to two critical limiting values, or, to design them with respect to a central value. [1].

\section{Pair-comparisons Method}

The pair comparisons (PC) method is in essence the basic method for the similarities/ dissimilarities method, and for the DBTS. The listener compares two excerpts at a time, and tries to find an inequality of the kind $S_{i}>S_{j}$ or reverse. The results of the comparison are ordered in a preference matrix as in Fig 4 a). 


$\begin{array}{cccccccc} & S a & S b & S c & \ldots & S j & \ldots & S n \\ S a & p_{a>a} & p_{b>a} & p_{c>a} & & p_{j>a} & & p_{n>a} \\ S b & p_{a>b} & p_{b>b} & p_{c>b} & & p_{j>b} & & p_{n>b} \\ S c & p_{a>c} & p_{b>c} & p_{c>c} & & p_{j>c} & & p_{n>c} \\ S j & p_{a>j} & p_{b>j} & p_{c>j} & & p_{j>j} & & p_{n>j} \\ S n & p_{a>n} & p_{b>n} & p_{c>n} & & p_{j>n} & & p_{n>n}\end{array}$

Fig. 4. a) Pair comparisons matrix

b) Structure of a pair comparisons' test

The structure of the PC method is depicted in Fig. 4. b). The presentation of the stimuli is performed in pairs and the listener task is to judge which of the two stimuli is bigger, louder, etc., in a specific dimension. The number of all possible pairs which is possible to assemble without repetition is

$$
C_{2}(n)=\frac{n(n-1)}{2}=0.5\left(n^{2}-n\right)
$$

With repetition the formula transforms into the variation,

$$
V_{2}(n)=n(n-1)=n^{2}-n
$$

\section{$5.1 \quad$ Reliability of the method}

While the methods of Successive Categories relied on the $t$-test for the measurement of reliability and ANOVA for the measurement of the validity, the method of pair comparisons relies on coefficients of agreement and the consistence coefficient.

\section{The method of similarities/dissimilarities}

In this method, the experimenter presents to the listener pairs of stimuli, and the listener's task is to evaluate the degree of similarity/dissimilarity between each pair of them.

A similarity/dissimilarity matrix is obtained and the results are processed via MDS (multidimensional scaling), FA (factor analysis), cluster analysis or other related statistical methods.

This model gives rise to the distance model, based on the concept of distance $d$. This distance $d$ between points of the model configuration represents the obtained experimentally dissimilarity $\delta$. It requires therefore as input data for the analysis, the dissimilarity values.

For the subjective measurement of similarities of acoustic stimuli, the direct comparison of all pairs of stimuli is used in the work. The listener's task is to express in a definite 
scale the degree of similarity between each pair on a bipolar scale, where its end points are perfect similarity and minimal similarity.

Observations made for a pair of objects, $i$ and $j$, result in a proximity value $p_{i j}$. The term proximity is used in a generic way to denote both similarity and dissimilarity. A nine point similarity scale is depicted in Fig 5 . When the observer finds minimal similarity between a pair of objects, the listener response corresponds to the left side of the scale. In the opposite case, the listener response should be positioned in the right side of the scale.

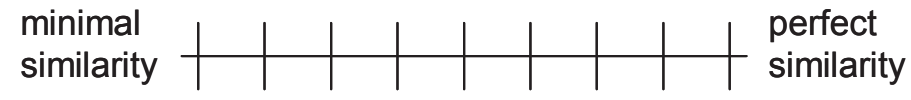

Fig. 5. The dissimilarity scale

\section{Other psychometric methods}

There exist a wide range of other methods which are explained briefly in the following lines.

\subsection{The method of Average Error}

Two stimuli are presented in this method by the experimenter: a fixed stimulus $S_{0}$, and a variable stimulus $S_{v}$. The task of the observer is to adjust the stimulus $S_{v}$ until he experiences the equality between $S_{0}$ and $S_{v}$. It is often called therefore the method of reproduction, the method of adjustment or the method of equivalent stimuli. In this method, nevertheless, a comparative judgment is not performed. The listener makes another mental operation instead, the equivalence one.

\subsection{The method of minimal changes}

A set of stimuli is presented in this method by the experimenter to the listener. The aim of the observer is to identify where he experiences a jnd (just noticeable difference) or a jnnd (just not noticeable difference) in the sequence. Therefore the presentation of the stimuli is arranged in an increasing order or in a decreasing one. The limen is situated somewhere between the $j$ nd and the jnnd. A computation of a point of subjective equality is also performed.

\subsection{The method of rank order}

A set of stimuli is presented in this method by the experimenter to the listener. The task of the observer is to place the stimuli in a descending/ascending order according to some feature or attribute. Comparative judgments are therefore made between each pair of stimuli. While in the Pair Comparison the order is made by steps, after comparing each stimulus with other, in the Rank Order method, the observer makes the order arrangement in one step. Apparently, internal consistency is here greater than in the method of Pair Comparisons.

Processing of the results is made by arranging the results in a so-called rank-order frequency matrix. In this matrix, the columns are formed with the stimuli, and the rows by 
the ranks. In each matrix cell, the frequency of a definite rank-order for a definite stimulus is obtained.

\subsection{Methods hased on Scaling from Interval Judgments}

In these methods, as for example the method of Equal Sense Distances, a set of stimuli is presented to the observer. Initially, two stimuli are presented, the boundary points of the experiment, $S_{1}$ and $S_{3}$. Presented a third stimulus $S_{2}$, the task of the observer is to place $S_{2}$ between $S_{1}$ and $S_{3}$ in order to obtain equal distances, $S_{3}-S_{2}=S_{2}-S_{1}$. The task is performed until all stimuli are evaluated.

\subsection{Methods based on ratio judgments}

In these methods, the experimenter presents to the observer a set of stimuli. The task of the observer is to find a stimulus $S_{x}$ being the half, the third, or some other ratio of the stimulus $S_{1}$, and to perform the procedure until every stimuli is evaluated. This is the basics for the method of fractionation. The procedure can be done inversely, and instead of ratios of stimuli, the experimenter can ask the listener to find a stimulus $S_{x}$ which is some multiple of a stimulus $S_{1}$. This means to find a stimulus $S_{x}$ as some multiple of $S_{1}$. The procedure is performed until every stimulus is evaluated. In the method of the constant-sum method, the observer is asked to report the ratio he experiences between two pairs of stimuli.

Finally, Tab. 2 [1] shows the most common features of psychometric methods.

\begin{tabular}{|l||l|l||}
\hline Main objective & Methods upon direct observation & Methods upon probabilities \\
\hline \hline Determination of equality of stimuli & Average errorMinimal changes & $\begin{array}{l}\text { Constant stimulus } \\
\text { Pair comparisons }\end{array}$ \\
\hline \hline Determination of rank order & $\begin{array}{l}\text { Rank order } \\
\text { Successive categories } \\
\text { Rating methods }\end{array}$ & $\begin{array}{l}\text { Pair comparisons } \\
\text { Unfolding }\end{array}$ \\
\hline \hline Determination of equality of intervals & & $\begin{array}{l}\text { Pair comparisons } \\
\text { Rank order } \\
\text { Triads } \\
\text { Tetrads } \\
\text { Successive categories } \\
\text { Similar reactions } \\
\text { Balanced values }\end{array}$ \\
\hline \hline \multirow{2}{*}{ Determination of ratios } & $\begin{array}{l}\text { Equal sense distances } \\
\text { Equal appearing intervals }\end{array}$ & \\
& & \\
\hline
\end{tabular}

Tab. 2. Classification of the psychometric methods [1]

\section{Conclusions}

A review of the suitable psychometric methodologies in the evaluation of different systems has been done. In this case, the research is focused on finding reliable methods for the evaluation of psychological disorders in the human being. The research began with the classic methods, as the constant ones, and it described more sophisticated methods for this kind of evaluation. Final remarks are made in order to classify these methods, and to visualize the more suitable ones for the purposes of the task. 


\section{References}

[1] J.P. Guilford, Psychometric methods, McGraw-Hill, Second Edition, 1954.

[2] E. Zwicker, H. Fastl, Psychoacoustics: Facts and Models, Springer, 1990.

[3] J. Stepanek, «Interpretation and comparison of perceptual spaces», in Inter-Noise 2005, Rio de Janeiro, 2005, CD-ROM, file:/papers/doc_1627.pdf

[4] S. Bech, N. Zacharov, Perceptual Audio Evaluation. Theory, Method and Application. Wiley, 2006.

[5] L.J. Cronbach, Prospects for a psychometric theory based on utility measure.1954.

[6] R. P. Hinton, Statistics Explained, Routledge, New York. 2004.

[7] N. Waller, F. W. Putnam, E. B. Carlson, Types of dissociation and dissociative types: A taxometric analysis of dissociative experiences. In «Psychological Methods», Vol 1(3), Sep 1996, pp. 300-321.

[8] T. M. Keane, J. M. Caddell, K. L. Taylor, Mississippi Scale for Combat-Related Posttraumatic Stress Disorder: Three studies in reliability and validity. In Journal of Consulting and Clinical Psychology, Vol 56(1), Feb 1988, pp. 85-90.

[9] P. C. Kendall, Treating anxiety disorders in children: Results of a randomized clinical trial. In Journal of Consulting and Clinical Psychology, Vol 62(1), Feb 1994, pp. 100-110.

[10] E. J. Ozer, S. R. Best, T. L. Lipsey, D. S. Weiss, Predictors of posttraumatic stress disorder and symptoms in adults: A metaanalysis. In Psychological Bulletin, Vol 129(1), Jan 2003, pp. 52-73. 